\title{
Correction to: Using Multiple Methods to Describe Supports for the Transition from Head Start to Kindergarten
}

\author{
Kyle DeMeo Cook ${ }^{1} \cdot$ Rebekah Levine Coley ${ }^{2}$
}

Published online: 17 November 2020

(c) Springer Nature B.V. 2020

\section{Correction to: Early Childhood Education Journal https://doi.org/10.1007/s10643-020-01085-x}

The original version of this article was missing some information in the Acknowledgement section.

Hence, the complete revised Acknowledgement section is given below:

Acknowledgement The Head Start Child and Family Experiences Survey (FACES), which is used as one of the data sources for this study, was provided by Child Care \& Early Education Research Connections (ICPSR34558) and funded by the United States Department of Health and Human Services, Administration for Children and Families, Office of Planning, Research and Evaluation (HHSP23320092900YC). Those who carried out the original data collection and analysis bear no responsibility for further analysis and interpretation. FACES data are maintained and distributed by the Child and Family Data Archive through the Inter-University Consortium for Political and Social Research (ICPSR) at the University of Michigan. It can be accessed at https://www.icpsr.umich.edu/icpsrweb/ICPSR/ studies/34558.

The authors would also like to thank Kathryn Zimmermann for her contributions to the project, the Head Start directors who participated in the primary data collection for the study, and the advisory committee that provided guidance throughout the project.

Publisher's Note Springer Nature remains neutral with regard to jurisdictional claims in published maps and institutional affiliations.
The original article can be found online at https://doi.org/10.1007/ s10643-020-01085-x.

Kyle DeMeo Cook cookk@stjohns.edu

1 St. John's University, 8000 Utopia Parkway, Jamaica, NY 11439, USA

2 Boston College, Chestnut Hill, MA, USA 